\title{
Intercircuit Control of Motor Pattern Modulation by Presynaptic Inhibition
}

\author{
Marlene Bartos and Michael P. Nusbaum \\ Department of Neuroscience, University of Pennsylvania School of Medicine, Philadelphia, Pennsylvania 19104
}

\begin{abstract}
Rhythmically active neural networks can control the modulatory input that they receive via their synaptic effects onto modulatory neurons. This synaptic control of network modulation can occur presynaptically, at the axon terminals of the modulatory neuron. For example, in the crab stomatogastric ganglion (STG), a gastric mill network neuron presynaptically inhibits transmitter release from a modulatory projection neuron called modulatory commissural neuron 1 . We showed previously that the gastric mill rhythm-timed presynaptic inhibition of the STG terminals of MCN1 is pivotal for enabling MCN1 to activate this rhythm. We also showed that MCN1 excites the pyloric rhythm within the STG. Here we show that, because MCN1 stimulation conjointly excites the gastric mill and pyloric rhythms, the gastric mill rhythm-timed presynaptic inhibition of MCN1
\end{abstract}

causes a rhythmic interruption in the MCN1-mediated excitation of the pyloric rhythm. Consequently, during each protraction phase of the gastric mill rhythm, presynaptic inhibition suppresses MCN1 excitation of the pyloric rhythm, thereby weakening the pyloric rhythm. During the retraction phase, presynaptic inhibition is absent and MCN1 elicits a faster, stronger, and modified pyloric rhythm. Thus, in addition to its role in enabling a neural circuit to regulate the modulatory transmission that it receives, presynaptic inhibition is also used effectively to rhythmically control the activity level of a distinct, but behaviorally related, neural circuit.

Key words: presynaptic inhibition; pyloric rhythm; gastric mill rhythm; Cancer borealis; stomatogastric nervous system; neuromodulation
Neuromodulatory influences enable neural networks to generate multiple activity patterns (Pearson, 1993; Steriade et al., 1993; Grillner et al., 1995; Marder et al., 1995; Marder and Calabrese, 1996). This results from the ability of neuromodulators to alter the membrane properties and synaptic efficacy of network neurons (Harris-Warrick et al., 1992b; Wang and McCormick, 1993; McCormick and Bal, 1994; Katz, 1995; Katz and Frost, 1995a,b). Neuromodulation also can alter the coordination between distinct, but related, neural networks (Dickinson, 1995). However, there are few studies that document the pathways mediating network-network interactions, and how they change with neuromodulation (Dickinson et al., 1990; Meyrand et al., 1991, 1994; Perrins and Weiss, 1996).

The accessibility of the crustacean stomatogastric nervous system (STNS) makes it ideal for studying both neural network modulation and intercircuit interactions (Selverston and Moulins, 1987; Harris-Warrick et al., 1992a; Marder et al., 1995). The STNS consists of the paired commissural ganglia (CoGs), the esophageal ganglion (OG), and the stomatogastric ganglion (STG). Overlapping subsets of STG neurons generate the gastric mill and pyloric rhythms (Weimann et al., 1991; Weimann and Marder, 1994). Modulatory inputs to the STG enable it to generate several distinct gastric mill and pyloric rhythms (Dickinson and Moulins, 1992; Harris-Warrick et al., 1992b; Marder and

\footnotetext{
Received Dec. 5, 1996; accepted Dec. 24, 1996.

This research was supported by National Institutes of Neurological Disorders and Stroke Grant NS-29436 and National Science Foundation Grant IBN94-96264 to M.P.N., a fellowship from the Deutsche Forschungsgemeinschaft to M.B., and the Human Frontiers Science Program. We thank Melissa Coleman for providing Figure $5 B$ and Dawn Blitz for reading and commenting on this manuscript.

Correspondence should be addressed to Dr. Michael P. Nusbaum, Department of Neuroscience, University of Pennsylvania School of Medicine, 215 Stemmler Hall, Philadelphia, PA 19104-6074.

Copyright (C) 1997 Society for Neuroscience $0270-6474 / 97 / 172247-10 \$ 05.00 / 0$
}

Weimann, 1992; Norris et al., 1994). In the crab Cancer borealis, most modulatory inputs to the STG originate in the CoGs (Coleman et al., 1992). In this species, there appear to be fewer than 25 different projection neurons innervating the STG (Coleman et al., 1992). Six of these projection neurons have been studied (Nusbaum and Marder, 1989a,b; Katz and HarrisWarrick, 1990; Coleman et al., 1993, 1995; Coleman and Nusbaum, 1994; Norris et al., 1994, 1996).

One of these identified projection neurons is modulatory commissural neuron 1 (MCN1) (Nusbaum et al., 1992; Coleman and Nusbaum, 1994; Coleman et al., 1995). There is a single MCN1 in each CoG. Each MCN1 arborizes in its ganglion of origin and in the STG. MCN1 stimulation elicits both a gastric mill rhythm and a pyloric rhythm (Nusbaum et al., 1992). The gastric mill rhythm elicited by MCN1 results partly from the fact that the timing of MCN1 neurotransmitter release onto gastric mill neurons in the STG is regulated by rhythmic presynaptic inhibition that MCN1 receives from a gastric mill neuron (Coleman and Nusbaum, 1994; Coleman et al., 1995).

In this paper, we document that the gastric mill rhythm-timed presynaptic inhibition of MCN1 also controls the MCN1 excitation of the pyloric rhythm. Thus, during each retraction phase of the gastric mill rhythm, MCN1 transmitter release excites the pyloric rhythm. During each protraction phase, presynaptic inhibition of MCN1 removes its excitation of the pyloric rhythm.

Some of these data were published previously in abstract form (Bartos and Nusbaum, 1996).

\section{MATERIALS AND METHODS}

Animals. Adult male crabs (C. borealis) were purchased from Commercial Lobster (Boston, MA) and the Marine Biological Laboratory (Woods Hole, MA). Crabs were maintained in aerated artificial seawater at $10-12^{\circ} \mathrm{C}$. Before dissection, crabs were cold-anesthetized by packing them in ice for $20-40 \mathrm{~min}$. The first stage of the dissection involved 
removing the foregut and the adjacent STNS from the crab, after which the STNS was dissected away from the foregut. Dissections were performed in saline at $\sim 4^{\circ} \mathrm{C}$. Data were obtained from 58 crabs.

Electrophysiology. All experiments were performed on the isolated STNS, including the four interconnected ganglia and their motor nerves (Fig. 1A). The CoGs are relatively large (each contains $\sim 500$ neurons), whereas the OG and STG are considerably smaller, containing $\sim 14$ neurons and $\sim 25$ neurons, respectively (Selverston and Moulins, 1987; Kilman and Marder, 1996). The STNS was pinned down in a silicone elastomer (SYLGARD 184, Dow Corning, Arlington, TN)-lined Petri dish and superfused continuously $(7-12 \mathrm{ml} / \mathrm{min})$ with chilled physiological saline $\left(10-12^{\circ} \mathrm{C}\right)$. C. borealis physiological saline contained (in $\mathrm{mM}$ ): 440 $\mathrm{NaCl}, 11 \mathrm{KCl}, 26 \mathrm{MgCl}_{2}-6 \mathrm{H}_{2} 0,13 \mathrm{CaCl}_{2}-2 \mathrm{H}_{2} \mathrm{O}, 10$ Trizma base, 5 maleic acid, $\mathrm{pH} 7.4-7.6$.

To facilitate intracellular recordings, the STG and CoGs were desheathed and visualized with light transmitted through a dark-field condenser (Nikon, Melville, NY). Intracellular recordings were made using microelectrodes (15-30 M $\Omega$ ) filled with $4 \mathrm{M}$ potassium-acetate plus $20 \mathrm{mM} \mathrm{KCl}$. Intra-axonal recordings were made with the same microelectrodes filled with $1 \mathrm{M} \mathrm{KCl}$. Intracellular current injections were done via single-electrode discontinuous current clamp (DCC, sample rate $\sim 3$ $\mathrm{kHz}$ ) using Axoclamp 2 amplifiers (Axon Instruments, Foster City, CA). Individual extracellular recordings were made by isolating a section of nerve, plus some saline, from the surrounding saline with petroleum jelly (Vaseline, Chesebrough-Ponds, Greenwich, CT) and pressing a stainless steel or platinum wire electrode, referenced to ground, into the SYLGARD within the Vaseline well. Intra- and extracellular recordings were collected onto chart recorder paper (MT-95000, Astro-Med, West Warwick, RI). Figures were prepared by scanning recordings into the CorelDraw (Version 3.0) graphics program via Scanjet IIc (Hewlett-Packard, Palo Alto, CA).

Intracellularly recorded STG neurons were identified by standard criteria, including the activity pattern of each neuron, their synaptic interactions with other STG neurons, and by performing simultaneous intra- and extracellular recordings to determine the identified nerves into which each neuron projected (Weimann et al., 1991; Coleman and Nusbaum, 1994; Norris et al., 1994, 1996; Coleman et al., 1995). In most experiments, influences within the STG from spontaneously active projection neurons that either originated in or projected through the CoGs were suppressed by bilateral transection of the ions and sons (Fig. $1 A$ ). In such nerve-transected preparations in $C$. borealis, there is no spontaneous gastric mill rhythm and the pyloric rhythm is either slower and less vigorous, or it terminates (Selverston and Moulins, 1987; Harris-Warrick et al., 1992a).

In most experiments, MCN1 was activated selectively by extracellular stimulation of the ion (Coleman, 1995; Coleman et al., 1995). To ensure that each ion stimulus elicited an MCN1 action potential, we maintained an intracellular recording of the lateral gastric (LG) neuron, although the $\mathrm{LG}$ recording is not included in all figures. Each MCN1 action potential elicits an electrical excitatory postsynaptic potential (E-EPSP) in LG (Coleman et al., 1995). MCN1 is the only neuron with an axon in the ion that elicits EPSPs in LG. In a few experiments $(n=4)$, we confirmed that the pyloric system response to intrasomatic stimulation of MCN1 was the same as from ion stimulation. The LG neuron also presynaptically inhibits MCN1 within the STG (Nusbaum et al., 1992; Coleman and Nusbaum, 1994) (Fig. 1C). Thus, to determine the extent of the pyloric network response to MCN1 stimulation, in some experiments we maintained sufficient hyperpolarizing current in LG to prevent it from firing spikes during MCN1 stimulation and thereby interfering with the MCN1 excitation of the pyloric rhythm.

Pyloric phase analysis. Each cycle of the pyloric rhythm includes three active phases (Fig. $1 B$ ). A pyloric rhythm cycle was defined as the interval between the onset of successive bursts in the pyloric dilator (PD) neuron, which is one of the complement of electrically coupled pyloric pacemaker neurons. In $C$. borealis, the pyloric pacemaker ensemble includes the single anterior burster $(\mathrm{AB})$ interneuron plus the paired $\mathrm{PD}$ and lateral posterior gastric (LPG) motor neurons (Weimann and Marder, 1994; Norris et al., 1996). This ensemble inhibits all other pyloric neurons. After pacemaker neuron activity, there is a brief silent period and then the inferior cardiac (IC) and lateral pyloric (LP) constrictor motor neurons fire impulse bursts. During the third phase of the pyloric cycle, activity occurs in the pyloric (PY) constrictor and ventricular dilator (VD) motor neurons.

Phase is defined as the duration from cycle onset to the parameter of interest (e.g., burst onset or offset) divided by the cycle period. In each of six preparations, the mean phase onset and offset of all pyloric motor neurons were determined by calculating these values on a cycle-by-cycle basis for each of 10 successive pyloric cycles before, during, and after MCN1 stimulation and then determining the average value for each condition. Phase relationships were determined entirely from extracellular recordings. To this end, we used the $p d n$ for PD, the $l v n$ or $d v n$ for LP, the $m v n$ for IC and VD, and the pyn for PY and LPG activity (Fig. 1). Statistical analyses were performed using SigmaStat for Windows (Version 1.0, Jandel Scientific, San Rafael, CA).

\section{RESULTS \\ MCN1 activity excites the pyloric rhythm}

The pyloric rhythm is excited by activation of MCN1. During ongoing pyloric rhythms, such as that shown in Figure $2 A$, tonic MCN1 stimulation increased the pyloric cycle frequency and enhanced the activity level of many pyloric neurons $(n=48$ preparations). As shown in Figure $2 A$, this included increased activity in the LP, IC, and VD neurons. Commonly, the IC and VD neurons are not active during weakly cycling pyloric rhythms. Under these conditions, MCN1 stimulation rapidly initiated vigorous rhythmic activity in VD. In contrast, IC activity did not commence until several cycles later, and then remained at a relatively low level of activity. The pyloric rhythm response to MCN1 stimulation tended to increase steadily during the first several (2-5) cycles and then maintained a steady level of increased activity until MCN1 activity was terminated, even when stimulation was maintained for several minutes.

Note in Figure $2 A$ that, during MCN1 stimulation, LG remained subthreshold despite receiving excitatory drive from MCN1. LG activity was suppressed by intracellular injection of constant-amplitude hyperpolarizing current. The pyloric rhythm-timed membrane potential changes that occurred in LG result from inhibitory input that it receives from interneuron 1 (Int1; Fig. 1C) (Coleman et al., 1995). Int1 is an STG neuron that is rhythmically active with both the pyloric and gastric mill rhythms (Weimann et al., 1991; Norris et al., 1994; Coleman et al., 1995).

The enhanced pyloric rhythm often persisted after MCN1 stimulation was terminated. For example, the mean pyloric cycle frequency during the 10 cycles immediately after termination of MCN1 stimulation was significantly faster than the prestimulus cycle frequency, albeit significantly slower than that occurring during MCN1 stimulation (for both comparisons: $n=48$ preparations, Wilcoxon signed Rank test, $p<0.0001)$. In the experiment shown in Figure $2 A$, it took $16 \mathrm{sec}$ for the pyloric rhythm to return to control levels after $\sim 15 \mathrm{sec}$ of MCN1 stimulation. For many cycles, activity levels also remained higher than their prestimulus levels in several pyloric neurons. LP and IC activity, for example, routinely persisted at elevated levels for $>10$ cycles after MCN1 stimulation (Fig. $2 A$ ).

In these experiments, the pyloric rhythm response to MCN1 stimulation was not likely to result from activation of additional projection neurons in the CoG because the sons were transected in all experiments and all CoG neurons except MCN1 and MCN5 project to the STG via the son (Coleman et al., 1992; Coleman and Nusbaum, 1994; Norris et al., 1996). MCN5 was not activated in these experiments because MCN5 has a higher activation threshold than MCN1 to ion stimulation (Coleman, 1995). Moreover, the MCN5 influence in the STG is readily distinguished from the influence of MCN1 (Norris et al., 1996).

To demonstrate directly that excitation of the pyloric rhythm 


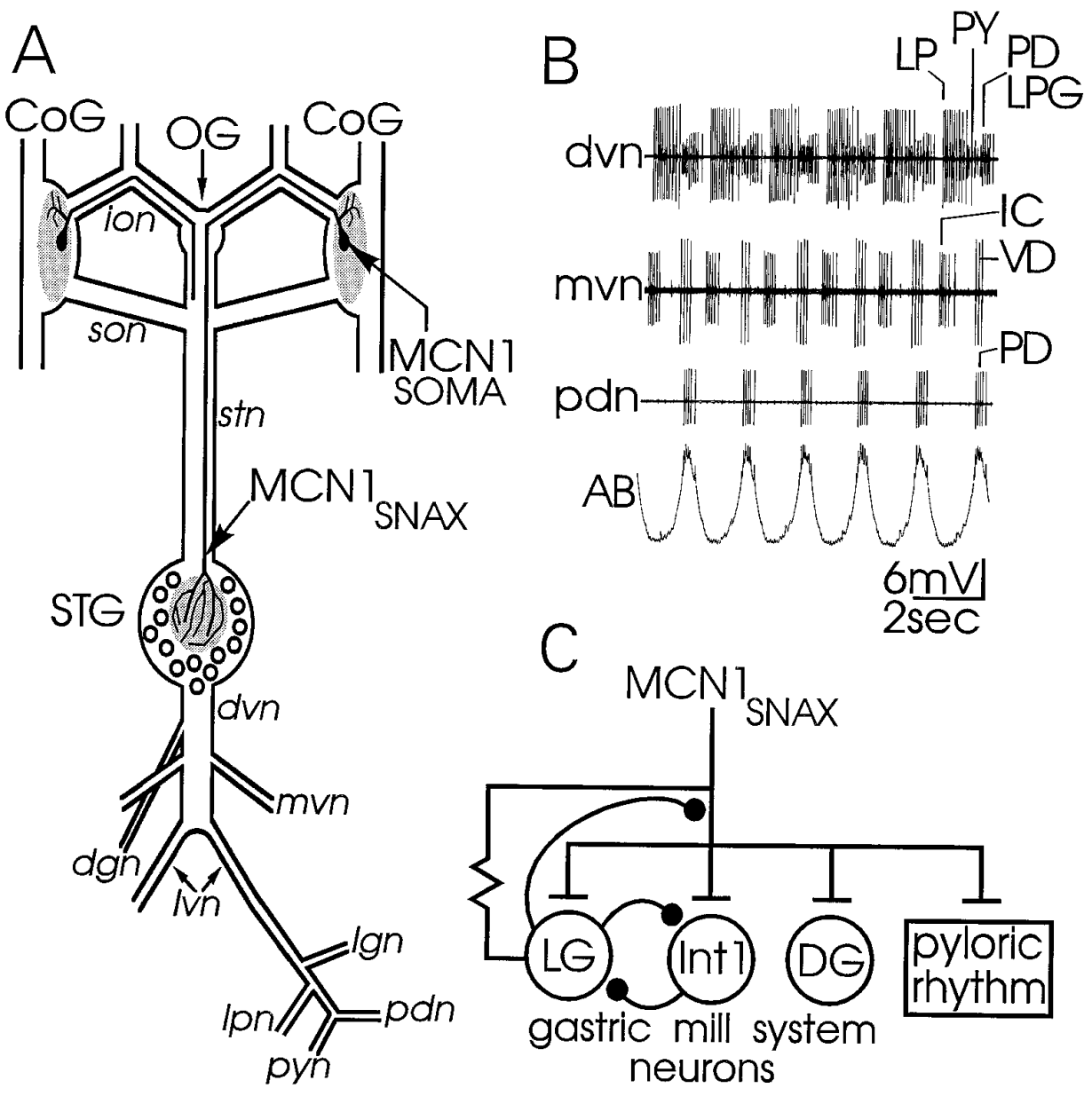

Figure 1. The stomatogastric nervous system (STNS) of the crab Cancer borealis. A, Schematic illustration of the STNS, including the soma location and branching pattern of MCN1. Stippled areas indicate neuropil regions. $B$, Combined intracellular and extracellular recordings of an ongoing pyloric rhythm. This is a three-phase motor pattern with consecutive impulse bursts in (1) $A B$, $P D$, and $L P G$; (2) $I C$ and $L P$; and (3) $P Y$ and $V D$. The LPG action potentials are recorded in the $d v n$, but they are obscured by the larger $P D$ spikes, with which they are coactive. Most hyperpolarized membrane potential: $A B,-58 \mathrm{mV}$. Abbreviations: (ganglia) $C o G$, commissural ganglion; $O G$, esophageal ganglion; $S T G$, stomatogastric ganglion; (nerves) $d g n$, dorsal gastric nerve; $d v n$, dorsal ventricular nerve; ion, inferior esophageal nerve; lgn, lateral gastric nerve; $l p n$, lateral pyloric nerve; $l v n$, lateral ventricular nerve; $m v n$, medial ventricular nerve; $p d n$, pyloric dilator nerve; pyn, pyloric nerve; son, superior esophageal nerve; stn, stomatogastric nerve; (interneurons) $A B$, anterior burster; $M C N 1$, modulatory commissural neuron 1 ; (motor neurons) $I C$, inferior cardiac constrictor; $L P$, lateral pyloric constrictor; $L P G$, lateral posterior gastric; $P D$, pyloric dilator; $P Y$, pyloric constrictor; $V D$, ventricular dilator. $C$, Schematic circuit diagram of the MCN1 influence on the gastric mill and pyloric systems. Symbols: $t$-bars indicate both fast and slow transmittermediated synaptic excitation; filled circles indicate transmitter-mediated synaptic inhibition; resistor symbol indicates electrical coupling. Based on data from Nusbaum et al. (1992), Coleman and Nusbaum (1994), and Coleman et al. (1995). during ion stimulation was attributable exclusively to activation of MCN1, we selectively suppressed MCN1 activity at the entrance to the STG while stimulating the ion (Fig. $2 B$ ). This was done by injecting hyperpolarizing current, via an intra-axonal recording electrode, into the stomatogastric nerve axon of MCN1 $\left(\mathrm{MCN1}_{\text {SNAX }}\right)$ (Coleman and Nusbaum, 1994). With sufficiently large hyperpolarizing current injection into $\mathrm{MCN}_{\mathrm{SNAX}}$, the action potentials elicited in MCN1 by ion stimulation failed to propagate actively into the STG. This is reflected in the loss of E-EPSPs in LG (data not shown). During this time, the excitation of the pyloric rhythm was eliminated and the rhythm returned to its prestimulation level (Fig. 2B). Removal of hyperpolarization from $\mathrm{MCN}_{\text {SNAX }}$ enabled its spikes to again propagate actively past the intra-axonal recording site and resume their excitation of the pyloric rhythm.

When there was no ongoing pyloric rhythm, MCN1 stimulation readily initiated this rhythm (Fig. $3 ; n=10$ preparations). The mean cycle frequency when rhythms were initiated was $0.74 \pm$ $0.14 \mathrm{~Hz}$. This was comparable to the cycle frequency attained during MCN1 stimulation of weakly $(<0.5 \mathrm{~Hz})$ cycling preparations. In contrast with the results obtained during already cycling rhythms, when MCN1 stimulation initiated the pyloric rhythm there was often no long-lasting effect evident after the stimulation ended (Fig. 3). Instead, the pyloric rhythm stopped either immediately after termination of MCN1 stimulation ( $n=5 / 10$ preparations) or outlasted MCN1 stimulation by $2-6$ cycles.

The $\mathrm{AB}$ interneuron is a conditional burster that drives the pyloric rhythm (Selverston and Miller, 1980; Moulins and Cournil,
1982; Hooper and Marder, 1987; Bal et al., 1988). Perhaps not surprisingly, then, the $\mathrm{AB}$ neuron response to $\mathrm{MCN} 1$ stimulation paralleled the pyloric cycle frequency response. Thus, MCN1 activity increased the amplitude and frequency of the membrane potential oscillations in $\mathrm{AB}$ when the pyloric rhythm was cycling weakly before MCN1 stimulation, and it initiated oscillations in $\mathrm{AB}$ when the rhythm was not already cycling (Fig. 3). During vigorous pyloric rhythms, the $\mathrm{AB}$ oscillation amplitude was enhanced only slightly. We found no evidence for the presence of discrete PSPs in AB during MCN1 stimulation.

\section{MCN1-elicited pyloric motor pattern}

We analyzed and compared the phase relationships among the pyloric motor neurons before, during, and after MCN1 stimulation to determine whether, along with decreasing the pyloric cycle period, it also altered the activity pattern of the pyloric neurons ( $n=6$ preparations). To reduce possible variations in the pyloric system response to $\mathrm{MCN} 1$ stimulation that might result from differences in the strength of the pyloric rhythm before stimulation, we analyzed six preparations with comparable prestimulus pyloric cycle frequencies $(0.57 \pm 0.10 \mathrm{~Hz})$. These preparations increased their mean cycle frequency significantly $(0.86 \pm 0.17$ $\mathrm{Hz} ; p<0.001$, paired Student's $t$ test) during MCN1 stimulation. They then cycled more slowly, but still significantly faster than before stimulation $(0.65 \pm 0.12 \mathrm{~Hz} ; p<0.001$, paired Student's $t$ test), during the first 10 cycles after the end of this stimulation.

As shown in Figure 4, in these preparations MCN1 stimulation changed the duty cycle and phase of activity of most pyloric motor 
Figure 2. Excitation of the pyloric rhythm by tonic stimulation of MCN1. $A$, Excitation of an ongoing pyloric rhythm by MCN1 stimulation. MCN1 was activated, selectively, by tonic stimulation of the ion. Before MCN1 stimulation, there was a relatively weak, but regular, pyloric rhythm evident in the lvn, but little or no activity in $V D$ and $I C$ ( $m v n)$. Activation of MCN1 enhanced the pyloric rhythm, and this excitation persisted for $>10$ cycles after termination of MCN1 stimulation. Note that LG was maintained subthreshold for transmitter release by constantamplitude hyperpolarizing current injection. Preparation had both sons transected to reduce the background excitation to the pyloric rhythm from other spontaneously active projection neurons. $V_{\text {holding: }} L G$, $-88 \mathrm{mV}$. B, Evidence that the excitation of the pyloric rhythm resulting from ion stimulation is attributable solely to activation of MCN1. The stomatogastric nerve axon of MCN1 $\left(M C N 1_{S N A X}\right)$ was recorded intra-axonally near the entrance to the STG (Coleman and Nusbaum, 1994). During excitation of the pyloric rhythm that resulted from ion stimulation, each ion stimulus elicited an action potential in MCN1 that propagated to the STG and was recorded in $\mathrm{MCN} 1_{\text {SNAX }}$. Six seconds after the start of ion stimulation, MCN1 $1_{\text {SNAX }}$ was hyperpolarized by current injection to $-100 \mathrm{mV}$ (between the arrowheads), causing the MCN1 action potentials to fail to propagate actively past the SNAX recording site. Consequently, the pyloric rhythm returned to its prestimulus level of activity. The peak of each $M C N 1_{\text {SNAX }}$ action potential reached +20 $\mathrm{mV}$ when they occurred at $V_{\text {rest }}(-52$ $\mathrm{mV}$ ), but they only reached $-70 \mathrm{mV}$ when MCN1 $1_{\text {SNAX }}$ was held at $-100 \mathrm{mV}$. Note that the pyloric rhythm was again excited when the hyperpolarizing current was removed from MCN1 $1_{\text {SNAX }}$. Tonic, smallamplitude units in $m v n$ and $l v n$ are artifacts from ion stimulation.
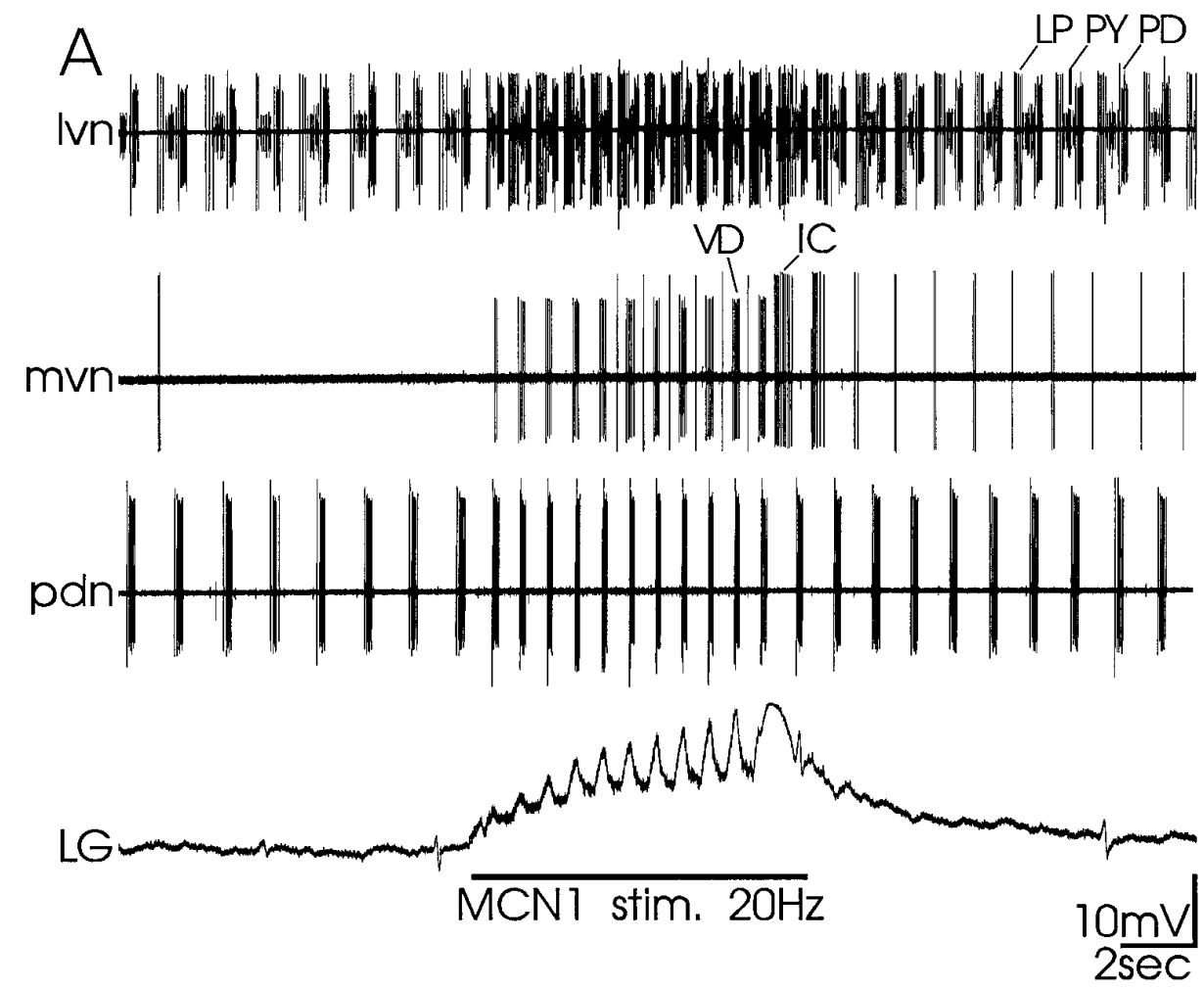

B
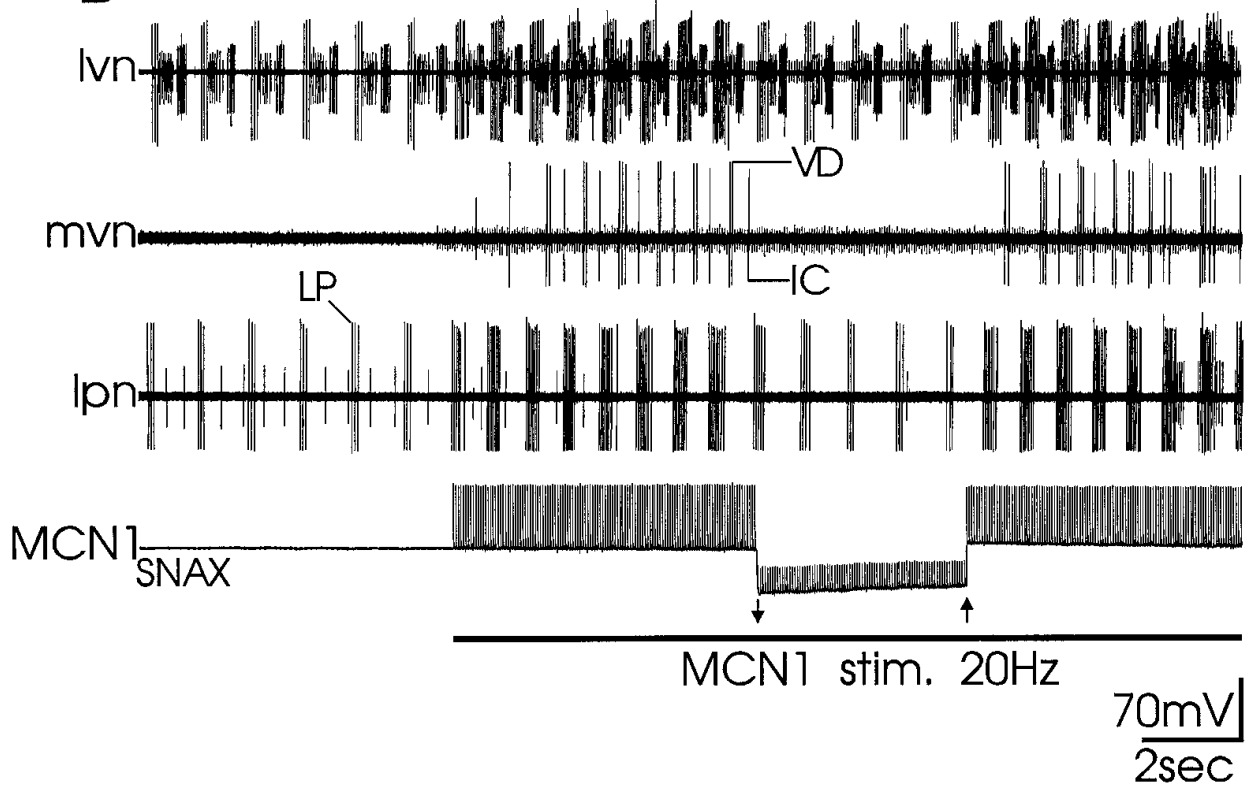

neurons. The duty cycle represents the mean fraction of the cycle during which a component neuron is active. During MCN1 stimulation, the duty cycle of the PD, LP, and VD neurons increased. For LP, the increased duty cycle resulted entirely from its burst terminating later in the cycle, whereas the increased VD duty cycle resulted from its burst activating earlier in the cycle. There was a significant decrease in the PY neuron duty cycle, with each PY burst starting significantly later in the cycle during MCN1 stimulation. There was considerably more overlap between the LP and PY bursts during MCN1 stimulation than under control conditions, despite the fact that the increased LP duty cycle was partly compensated by the decreased PY duty cycle. This increased amount of overlap was surprising because there is a reciprocal inhibitory connection between LP and PY that partly determines the timing of their bursts (Harris-Warrick et al., 1992b).

A second, distinct pyloric motor pattern occurred after termination of MCN1 stimulation (Fig. 4C). The PY and VD duty cycles returned to their prestimulus levels, but the PD and LP duty cycles remained significantly longer for at least 10 cycles. Addi- 


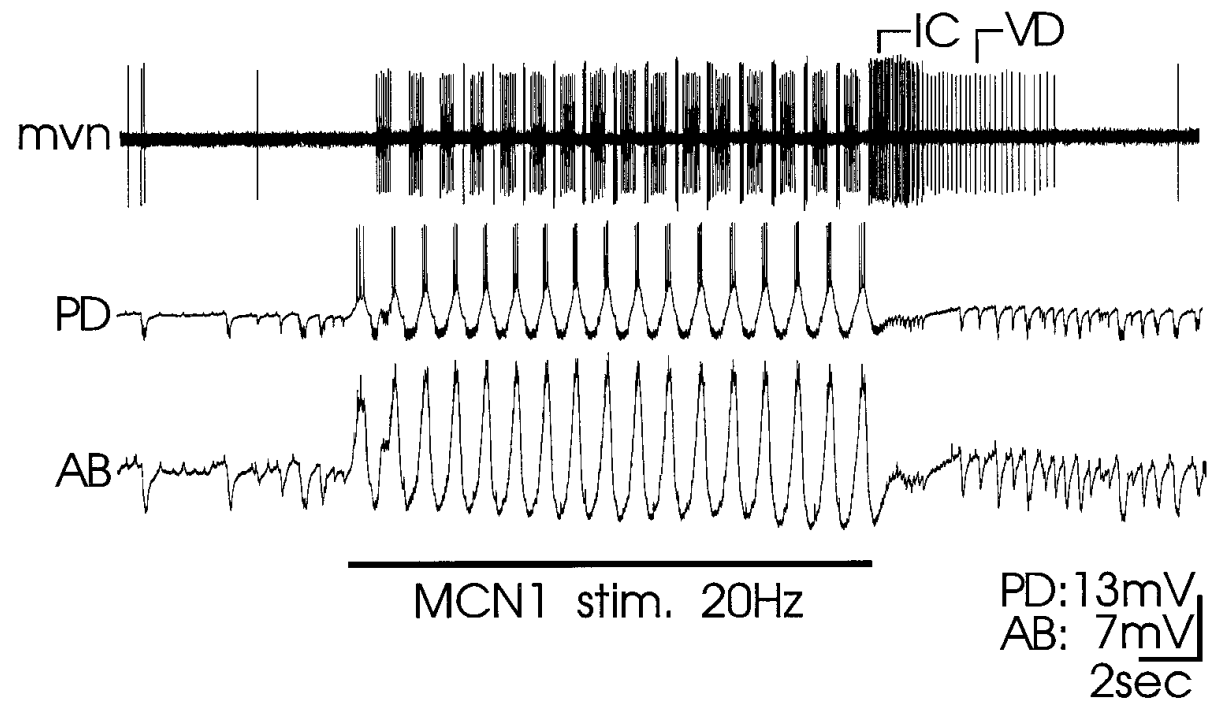

Figure 3. Initiation of the pyloric rhythm by MCN1 stimulation. Stimulation of MCN1 elicited the pyloric rhythm in this preparation, which had both sons transected and the LG neuron hyperpolarized (not shown). Note that the pyloric rhythm stopped as soon as stimulation was terminated. Most hyperpolarized membrane potential during pyloric rhythm: $A B,-64$ $\mathrm{mV} ; P D,-60 \mathrm{mV}$. tionally, the poststimulus duty cycles of LPG and IC were lengthened significantly compared with their prestimulus levels.

\section{Gastric mill rhythm-timed presynaptic inhibition of MCN1 influences the pyloric rhythm}

When LG is not hyperpolarized, MCN1 stimulation elicits a gastric mill rhythm as well as the pyloric rhythm (Nusbaum et al., 1992; Coleman and Nusbaum, 1994). A functionally important component of MCN1-elicited gastric mill rhythm generation is the presynaptic inhibition that $\mathrm{MCN} 1$ receives from $\mathrm{LG}$ during each protraction phase (Fig. 1C) (Coleman and Nusbaum, 1994; Coleman et al., 1995). We were interested to determine whether this presynaptic inhibition also influenced the excitatory effects of MCN1 on the pyloric rhythm. Therefore, we performed experiments in which we did not suppress LG activity with hyperpolarizing current, enabling MCN1 stimulation to conjointly elicit the gastric mill rhythm and excite the pyloric rhythm.

During these stimulations, we found that MCN1 activity significantly enhanced the pyloric cycle frequency only during each retraction phase of the gastric mill rhythm, when DG and Int1 are active and LG is silent (Dunn's $t$ test, $p<0.05$; $n=14$ preparations; see also Figs. 5, 6). Neither DG nor Int1 contributed to this MCN1-mediated excitation of the pyloric rhythm (data not shown) (see also Coleman, 1995). In contrast to the strengthened pyloric rhythm that occurred during each retraction phase, during each protraction phase the pyloric rhythm activity was reduced back toward control levels. Thus, when the pyloric rhythm either was not active or was intermittent before MCN1 stimulation, the pyloric rhythm was enhanced during each DG burst, but it often terminated during each LG burst (Fig. $5 A$ ). At these times, during each LG burst, LP and PY fired tonically while all other pyloric neurons were silent. This result was consistent with the hypothesis that the LG-mediated presynaptic inhibition of MCN1 was eliminating the MCN1 excitation of the pyloric rhythm during each protraction phase of the gastric mill rhythm. Further supporting this hypothesis was the fact that the pyloric rhythm also terminated immediately after MCN1 stimulation during times when LG activity was suppressed with hyperpolarizing current and the pyloric rhythm was either off or intermittent before to MCN1 stimulation (Fig. 3).

When the pyloric rhythm was cycling regularly before MCN1 stimulation, its rhythmic activity was reduced, but not terminated, during each LG burst (Figs. 5B,6). For example, the pyloric cycle frequency was significantly slower during each LG burst than during each DG burst (Figs. 5B2, $6 ; n=14$ preparations; $p<0.01$,
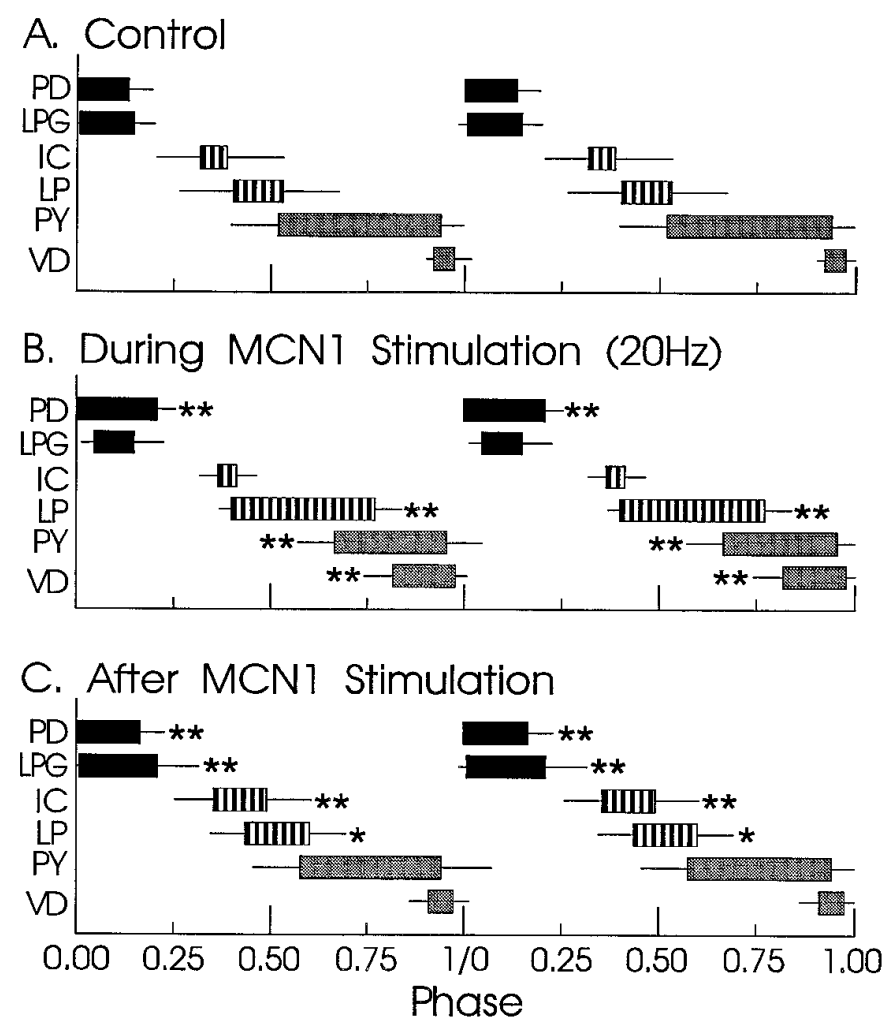

Figure 4. Phase relationships of the pyloric motor neurons before, during, and after MCN1 stimulation. The beginning and end of each box represent the mean \pm SD onset and offset times of the impulse burst in the indicated neuron, expressed as a fraction of the pyloric cycle period. The pyloric cycle extends from the onset of a PD neuron burst to the onset of its next burst. Two consecutive normalized pyloric cycles are shown. Results are pooled from six preparations, all of which had both ions and sons transected, and the LG neuron hyperpolarized by constant amplitude current injection. For each neuron, the onset and offset of activity in $B$ and $C$ were compared with the equivalent point in $A$, using the paired Student's $t$ test $\left({ }^{*} p<0.05 ; * * p<0.01\right)$. 
Figure 5. During conjoint activation of the gastric mill- and pyloric rhythms by MCN1 stimulation, there are gastric mill rhythm-timed reductions in pyloric rhythm activity. $A$, Influence of the gastric mill rhythm-timed LG burst when there was a weak pyloric rhythm before MCN1 stimulation. Left, Before MCN1 stimulation, the pyloric rhythm was weak and intermittent and there was no gastric mill rhythm (note the lack of LG activity). The DG neuron was bursting intermittently. Right, During MCN1 stimulation, the gastric mill rhythm was activated, as evident by the alternating bursts in DG and LG. When LG was not active, MCN1 activity excited the pyloric rhythm. However, this rhythm was terminated during each LG burst. Note that, during each LG burst, there was no activity in PD $(p d n)$ and only tonic activity in PY ( pyn). Tonically active unit in $d g n$ that is nearly the same amplitude as the DG neuron is the anterior gastric receptor (AGR) sensory neuron. $B 1$, Influence of the gastric mill rhythm-timed LG burst when there was a strong pyloric rhythm before MCN1 stimulation. Here, MCN1 stimulation activated the gastric mill rhythm and excited the pyloric rhythm. The pyloric rhythm slowed, but did not terminate, during each LG burst. MCN1 was activated via constant-amplitude intrasomatic depolarizing current injection beginning before the recording shown. B2, Expanded time scale. The effect of the gastric mill rhythm-timed presynaptic inhibition on the pyloric rhythm is evident in the reduced frequency of membrane potential oscillations in the pyloric pacemaker interneuron, $A B$, during each LG burst (single star) when compared with its frequency during the LG interburst interval (double star). The amplitude of the $\mathrm{AB}$ oscillations was also smaller during each LG burst. MCN1 firing frequency was $\sim 25 \mathrm{~Hz}$. Most hyperpolarized membrane potential: $M C N 1,-40 \mathrm{mV} ; L G,-64 \mathrm{mV} ; A B$, $-58 \mathrm{mV}$.
A
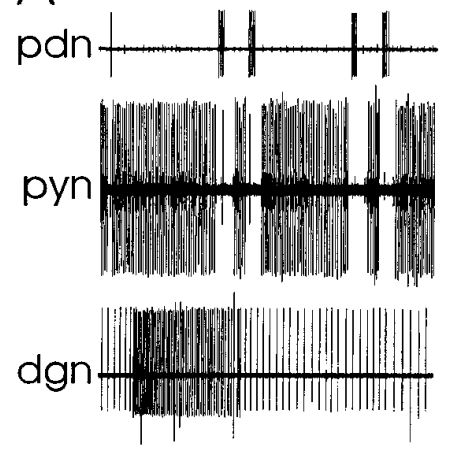

lgn

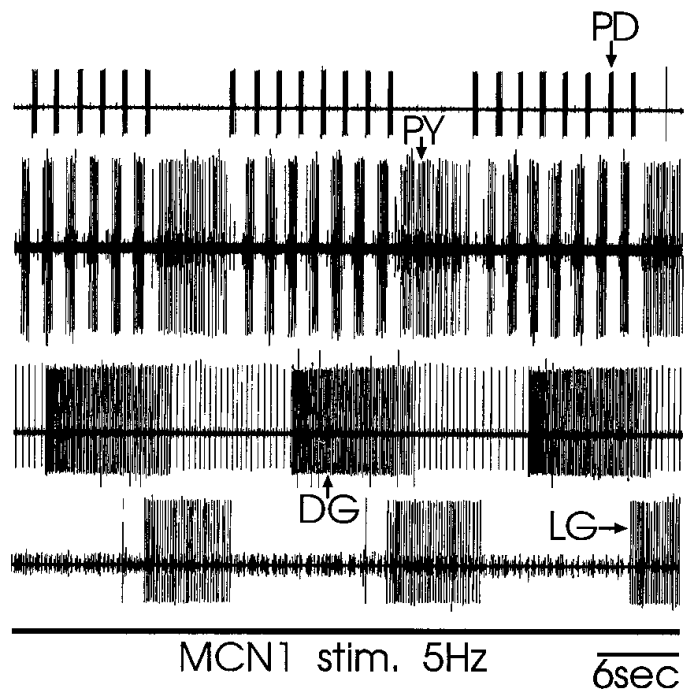

B1

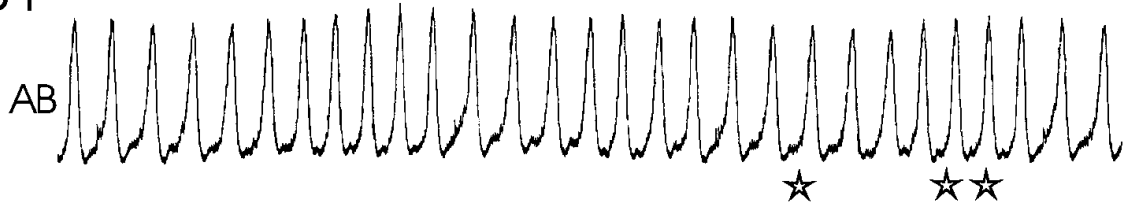

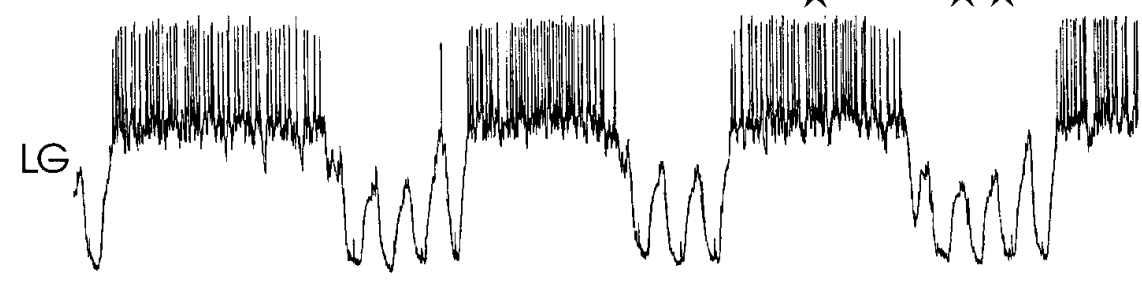

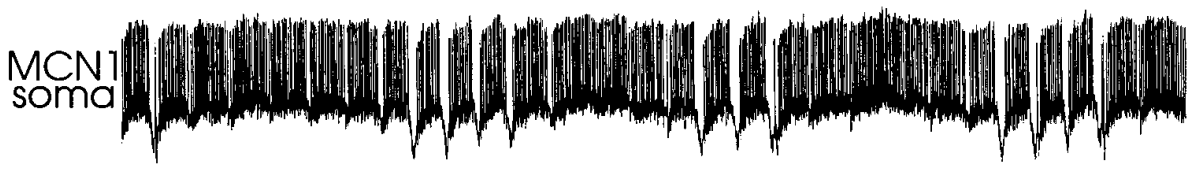

$\mathrm{B2}$

AB: $\quad 5 m V$ LG: $8 \mathrm{mV}$ MCN1: $6 \mathrm{mV}$

Student's $t$ test). In fact, the pyloric cycle frequency during these LG bursts was equivalent to that occurring during the first several cycles immediately after MCN1 stimulation (Fig. $6 ; n=14$ preparations; $p>0.05$, Student's $t$ test).

Supporting the hypothesis that the LG-mediated presynaptic inhibition of MCN1 was responsible for the gastric mill rhythmtimed weakening of the pyloric rhythm, we found that hyperpolarization of LG eliminated the rhythmic reduction in pyloric rhythm activity during MCN1 stimulation ( $n=4$; Fig. 7$)$. We also determined that, in the absence of MCN1 stimulation, LG activity did not alter the pyloric rhythm (Fig. 8). This was important to determine because LG has several synaptic links to the pyloric system. This includes its synaptic inhibition of VD and its electrical coupling with LP (Weimann and Marder, 1994; Coleman, 1995) (M. Coleman, B. Norris, and M. Nusbaum, unpublished data). One or both of these routes might have contributed significantly to the LG-mediated reduction in pyloric cycle frequency.

The pyloric cycle frequency is controlled primarily by the pyloric pacemaker neurons (Hooper and Marder, 1987). VD is electrically coupled to these neurons (Eisen and Marder, 1984; Weimann and Marder, 1994). Therefore, it was possible that the LG-mediated inhibition of VD would, via electrical coupling, hyperpolarize the pyloric pacemaker neurons and thereby reduce the rate of their rhythmic bursting. LP synaptically inhibits the 


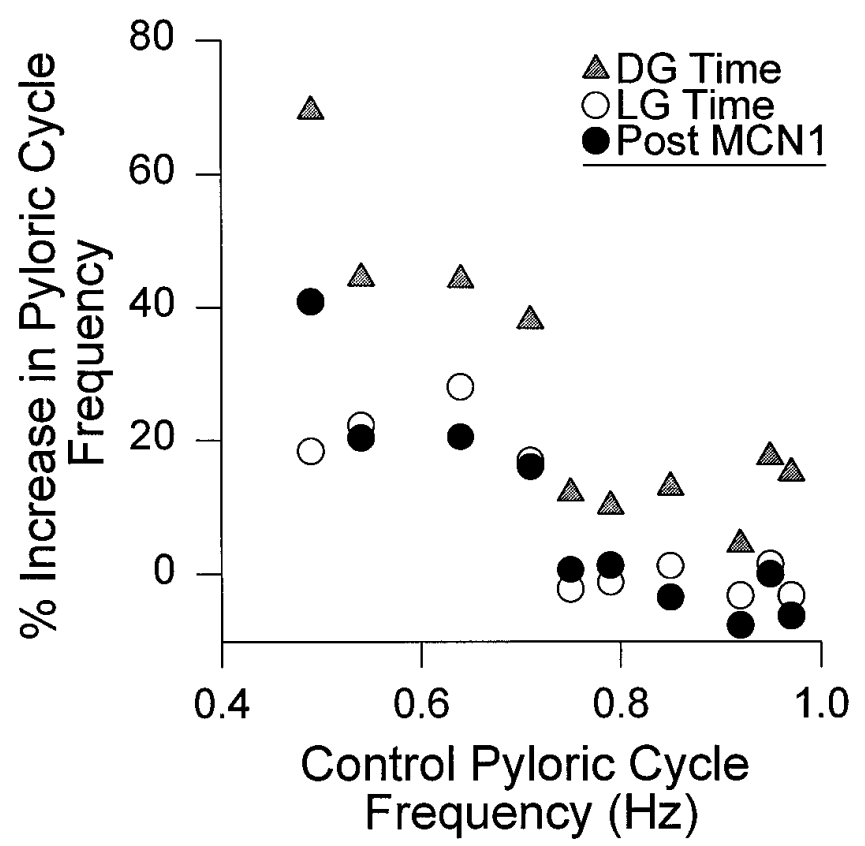

Figure 6. Percentage increase in pyloric cycle frequency elicited by MCN1 activity during the protraction (LG) and retraction (DG) phases of the gastric mill rhythm. These were compared with the pyloric cycle frequency during the first three cycles immediately after termination of MCN1 stimulation. The first three cycles poststimulation were selected for comparison because there are usually three pyloric rhythm cycles during each LG burst, and MCN1 transmitter release is either suppressed or reduced during the LG bursts. Data are plotted as a function of the mean pyloric cycle frequency for 10 cycles before each MCN1 stimulation. Each vertical set of three data points ( $D G$-timed, $L G$-timed, post-MCN1-timed) for a given control cycle frequency is from the same MCN1 stimulation. Results are shown from 10 of 14 preparations. The remaining four experiments involved control cycle frequencies already represented in this figure and gave results comparable to those shown.

pyloric pacemaker neurons (Eisen and Marder, 1984; Weimann and Marder, 1994). Therefore, it was possible that the electrical coupling between LG and LP was strong enough to enable each LG burst to strengthen the LP-mediated inhibition of the pacemaker neurons and thereby slow their rhythmic bursting. To document that LG did not influence the pyloric cycle frequency in the absence of MCN1 activity, we stimulated LG to fire bursts of action potentials in a gastric mill rhythm-like pattern, in the absence of MCN1 activity. We used LG intraburst firing frequencies (range: $9-18 \mathrm{~Hz} ; n=9$ preparations) that were comparable to its gastric mill rhythm-timed activity, which is $11.5 \pm 6.8 \mathrm{~Hz}$ (Norris et al., 1994). As shown in Figure 8, under these conditions there was no change in the pyloric cycle frequency, as occurs during LG bursts when MCN1 is active (Figs. 5-7).

\section{DISCUSSION}

\section{MCN1-mediated pyloric motor pattern}

Activation of MCN1, a modulatory projection neuron in the crab C. borealis, elicits a pyloric motor pattern that is distinct from the previously documented pyloric motor patterns in this species. One or more aspects of the phase relationships that characterize the MCN1-elicited pyloric rhythm differ from those occurring either during superfusion of different modulatory transmitters (Nusbaum and Marder, 1988; Harris-Warrick et al., 1992b; Marder and Weimann, 1992; Weimann et al., 1993; Skiebe and Schneider, 1994; Blitz et al., 1995) or activation of other modulatory projection neurons (Nusbaum and Marder, 1989b; Katz and HarrisWarrick, 1990; Norris et al., 1996).

One projection neuron in $C$. borealis that might be expected to influence the pyloric rhythm in a manner comparable to MCN1 is the modulatory proctolin neuron (MPN). This is because both neurons contain GABA and the neuropeptide proctolin (Nusbaum and Marder, 1989a; Nusbaum et al., 1989; Christie et al., 1993). However, the MPN-elicited pyloric rhythm is mimicked by proctolin superfusion (Nusbaum and Marder, 1989b), whereas the MCN1-elicited pyloric rhythm differs in several respects from both MPN stimulation and proctolin superfusion. For example, the PD and VD duty cycles are significantly longer during MCN1 stimulation. These differences may result from the presence of an additional neuropeptide, called $C$. borealis tachykinin-related peptide Ia (CabTRP Ia), in MCN1 (Christie et al., 1996). MCN1 is the only neuron innervating the STG that contains this neuropeptide, and superfusion of CabTRP Ia excites the pyloric rhythm (Blitz et al., 1995; Christie et al., 1996). However, the influence of CabTRP Ia on individual pyloric neurons, and the pyloric phase relationships that result from its co-application with proctolin, remains to be tested.

When there is a regularly cycling pyloric rhythm before MCN1 activation, the pyloric rhythm enhancement by MCN1 persists after its activity is terminated. This results in a second distinct pyloric motor pattern that is maintained for many cycles after MCN1 stimulation. Generation of a second distinct pyloric pattern after stimulation of a projection neuron also occurs with several of the other identified projection neurons in this system (Nagy and Dickinson, 1983; Meyrand et al., 1994; Katz and Harris-Warrick, 1990; Norris et al., 1996).

\section{Cross-circuit control by presynaptic inhibition}

Many behaviors involve coordinated activity between neural networks that control movements of different parts of the body, such

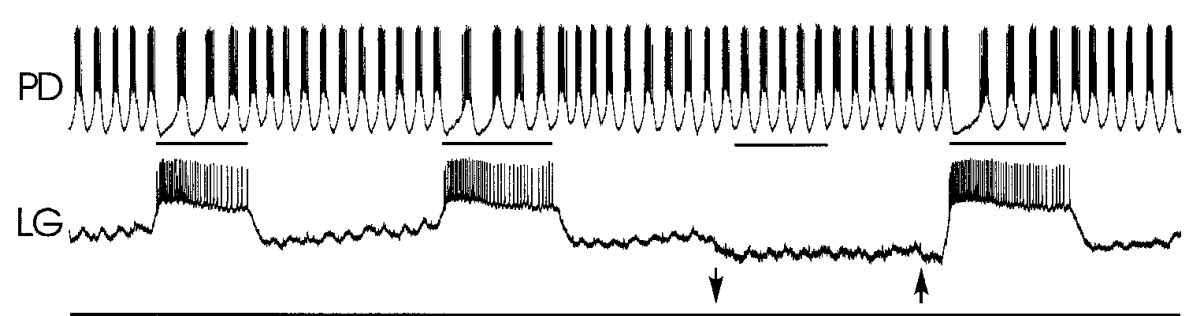

MCN1 stim. $20 \mathrm{~Hz}$
PD: $15 \mathrm{mV}$

LG: $\frac{8 \mathrm{mV}}{6 \mathrm{sec}}$
Figure 7. Elimination of LG neuron activity removed the rhythmic weakening of the pyloric rhythm that occurs during MCN1 stimulation. During MCN1 stimulation, the pyloric rhythm cycle frequency slowed during each gastric mill rhythm-timed LG burst ( first two bars). Suppression of the next anticipated LG burst by injection of constant amplitude hyperpolarizing current into LG (between arrows) eliminated the next anticipated reduction in the pyloric rhythm (third bar). Removal of hyperpolarizing current enabled LG to resume bursting, resulting again in reduced pyloric rhythm activity time-locked to each LG burst (fourth bar). Most hyperpolarized membrane potentials: $L G,-64 \mathrm{mV} ; P D,-54 \mathrm{mV}$. 


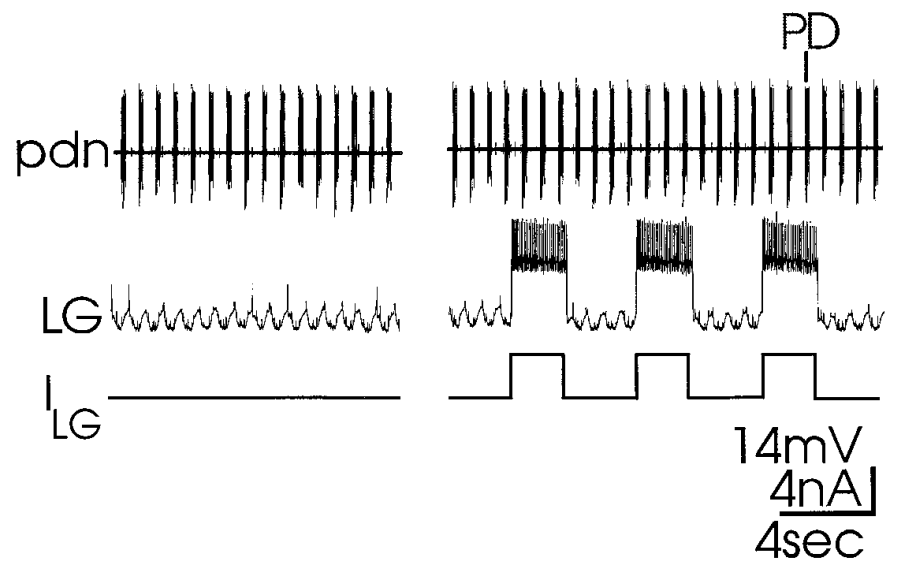

Figure 8. Imposed gastric mill rhythm-like bursts in LG do not mimic the LG-mediated reduction in pyloric rhythm activity that occurs during MCN1 stimulation. Left, Ongoing pyloric rhythm with no gastric mill rhythm and no activity in MCN1 (not shown). Right, Stimulating LG in gastric mill rhythm-like bursts did not interfere with the pyloric rhythm. The pyloric cycle frequency before, during, and in between LG stimulations is not significantly different (one-way ANOVA, $p>0.05 ; n=9$ preparations). Most hyperpolarized membrane potential: $L G,-64 \mathrm{mV}$.

as during locomotion (Freisen and Pearce, 1993; Mulloney et al., 1993; Grillner et al., 1995) or the ingestion, chewing, and processing of food (Dickinson et al., 1990; Weimann et al., 1991; Dickinson and Moulins, 1992; Weimann and Marder, 1994; Perrins and Weiss, 1996). Coordinated activity between distinct, but functionally related, neuronal networks has also been recorded for locomotion with respiration (Kawahara and Suzuki, 1990; Corio et al., 1993), locomotion with posture (Chrachri and Neil, 1993), and respiration with coughing, swallowing, and vocalizing (Otto and Hennig, 1993; Larson et al., 1994; Oku et al., 1994). In most cases, the cellular mechanisms subserving such coordination have not been determined (Dickinson, 1995).

The rhythmic movements of the gastric mill and pyloric regions of the stomach perform related functions. The gastric mill chews ingested food, whereas the pylorus controls the movement of chewed food from the stomach to the midgut (Johnson and Hooper, 1992; Heinzel et al., 1993). When the pyloric and gastric mill rhythms are co-active, they presumably exhibit coordinated activity in part because several STG neurons participate in the generation of both rhythms (Weimann et al., 1991; Weimann and Marder, 1994; Manor et al., 1996). For these multifunctional neurons, both their pyloric rhythm- and gastric mill rhythm-timed activity produces behaviorally useful movements in vivo (Heinzel et al., 1993). We have shown here that when MCN1 conjointly activates/modulates the pyloric and gastric mill rhythms, there is a further coordination between these two rhythms. Specifically, the pyloric rhythm response to MCN1 is rhythmically weakened by gastric mill rhythm-timed presynaptic inhibition of the STG terminals of MCN1 (Fig. 9). Interestingly, recent work involving electromyographic recordings in intact European lobsters (Homarus gammarus) indicates that a comparable gastric mill rhythmtimed influence on the pyloric rhythm occurs in vivo (Clemens et al., 1996). Whether these in vivo results also involve presynaptic inhibition of the MCN1 homolog in the lobster is undetermined.

In addition to producing a rhythmic reduction of the pyloric
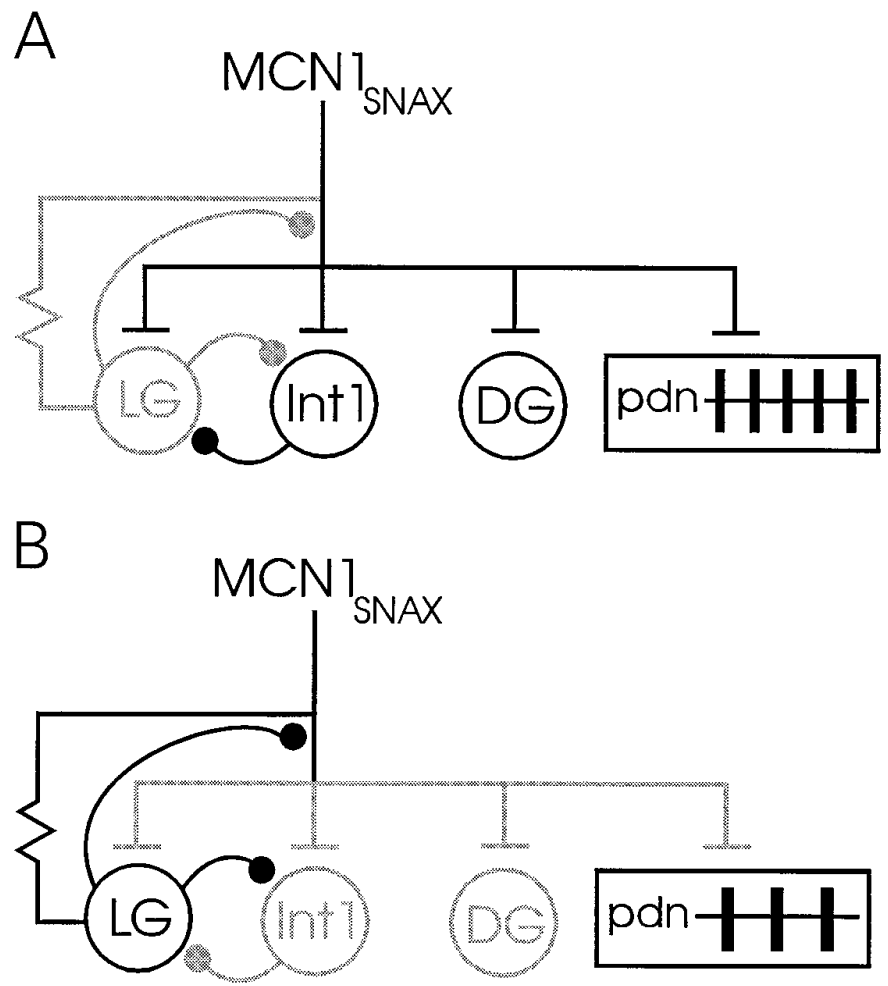

Figure 9. Schematic circuit diagram illustrating the relative influence of MCN1 on the pyloric rhythm (represented by the $p d n$ ) during the protraction and retraction phases of the gastric mill rhythm. $A$, During the retraction phase of the gastric mill rhythm, LG is synaptically inhibited by Int1, enabling MCN1 to have transmitter-mediated influences on the STG circuits (Coleman et al., 1995) (this article). B, During the protraction phase, LG fires a burst of action potentials that presynaptically inhibits the STG terminals of MCN1 (Coleman and Nusbaum, 1994; Coleman et al., 1995). This reduces or suppresses the transmitter-mediated effects of MCN1 on the gastric mill (Coleman et al., 1995)- and pyloric rhythms (this article). Active neurons are indicated by black shading; inactive neurons are indicated by gray shading. Symbols are the same as Figure $1 C$.

cycle frequency, the rhythmic presynaptic inhibition of MCN1 is likely to cause a corresponding rhythmic alteration in the pyloric neuron phase relationships. During each retraction phase of the gastric mill rhythm, when LG is silent and MCN1 is releasing its transmitters, the pyloric system phase relationships are likely to be equivalent to those that occurred when we stimulated MCN1 while suppressing LG activity with hyperpolarizing current (Fig. 4B). Similarly, during each protraction phase, when LG is active and presynaptically inhibiting MCN1, the pyloric phase relationships should be comparable to those that occurred immediately after the end of MCN1 stimulation (Fig. 4C) and different from the pyloric pattern that was occurring before MCN1 stimulation (Fig. 4A). We do not yet know the specific behavioral role subserved by this gastric mill rhythm entrainment of the state of the pyloric rhythm. It does, however, highlight a novel mechanism whereby coordination is produced between the comodulated activity patterns of distinct, but related, neural circuits.

\section{REFERENCES}

Bal T, Nagy F, Moulins M (1988) The pyloric central pattern generator in Crustacea: a set of conditional neuronal oscillators. J Comp Physiol [A] 163:715-727. 
Bartos M, Nusbaum MP (1996) Two proctolin/GABA neurons elicit distinct motor patterns from the same neural network. Soc Neurosci Abstr 22:1375.

Blitz DM, Christie AE, Marder E, Nusbaum MP (1995) Distribution and effects of tachykinin-like peptides in the stomatogastric nervous system of the crab, Cancer borealis. J Comp Neurol 354:282-294.

Chrachri A, Neil D (1993) Interactions and synchronization between two abdominal motor systems in crayfish. J Neurophysiol 69:1371-1383.

Christie AE, Norris BJ, Coleman MJ, Marder E, Nusbaum MP (1993) Neuropil arborizations and transmitter complement of a modulatory projection neuron. Soc Neurosci Abstr 19:931.

Christie AE, Lundquist T, Nässel DR, Nusbaum MP (1996) Two novel tachykinin-related peptides from the crab nervous system. Soc Neurosci Abstr 22:1375.

Clemens S, Meyrand P, Simmers J (1996) Dynamic interactions between motor pattern generating networks in the stomatogastric ganglion of intact lobster. Soc Neurosci Abstr 22:132.

Coleman MJ (1995) Dynamic modulation of a rhythmically active neural network in the stomatogastric nervous system of the crab, Cancer borealis. PhD thesis, University of Alabama at Birmingham.

Coleman MJ, Nusbaum MP (1994) Functional consequences of compartmentalization of synaptic input. J Neurosci 14:6544-6552.

Coleman MJ, Nusbaum MP, Cournil I, Claiborne BJ (1992) Distribution of modulatory inputs to the stomatogastric ganglion of the crab, Cancer borealis. J Comp Neurol 325:581-594.

Coleman MJ, Norris BJ, Nusbaum MP (1993) Functional modification of rhythmic motor activity by a modulatory projection neuron. Soc Neurosci Abstr 19:1701.

Coleman MJ, Meyrand P, Nusbaum MP (1995) A switch between two modes of synaptic transmission mediated by presynaptic inhibition. Nature 378:502-505.

Corio M, Palisses R, Viala D (1993) Origin of the central entrainment of respiration by locomotion facilitated by $\mathrm{MK} 801$ in the decerebrate rabbit. Exp Brain Res 95:84-90.

Dickinson PS (1995) Interactions among neural networks for behavior. Curr Opin Neurobiol 5:792-798.

Dickinson PS, Moulins M (1992) Interactions and combinations between different networks in the stomatogastric nervous system. In: Dynamic biological networks: the stomatogastric nervous system (Harris-Warrick RM, Marder E, Selverston AI, Moulins M, eds), pp 139-160. Cambridge, MA: MIT.

Dickinson PS, Mecsas C, Marder E (1990) Neuropeptide fusion of two motor pattern generator circuits. Nature 344:155-158.

Eisen JS, Marder E (1984) Mechanisms underlying pattern generation in lobster stomatogastric ganglion determined by selective inactivation of identified neurons. III. Synaptic connections of electrically coupled pyloric neurons. J Neurophysiol 48:1392-1415.

Freisen WO, Pearce RA (1993) Mechanisms of intersegmental coordination in leech locomotion. Semin Neurosci 5:41-47.

Grillner S, Deliagina T, Ekeberg Ö, El Manira A, Hill RH, Lansner A, Orlovsky GN, Wallén P (1995) Neural networks that co-ordinate locomotion and body orientation in lamprey. Trends Neurosci 18:270-279.

Harris-Warrick RM, Marder E, Selverston AI, Moulins M (1992a) Dynamic biological networks: the stomatogastric nervous system. Cambridge, MA: MIT.

Harris-Warrick RM, Nagy F, Nusbaum MP (1992b) Neuromodulation of stomatogastric networks by identified neurons and transmitters. In: Dynamic biological networks: the stomatogastric nervous system (Harris-Warrick RM, Marder E, Selverston AI, Moulins M, eds), pp 87-138. Cambridge, MA: MIT.

Heinzel H-G, Weimann JM, Marder E (1993) The behavioral repertoire of the gastric mill in the crab, Cancer pagurus: an in situ endoscopic and electrophysiological examination. J Neurosci 13:1793-1803.

Hooper SL, Marder E (1987) Modulation of the lobster pyloric rhythm by the peptide proctolin. J Neurosci 7:2097-2112.

Johnson BR, Hooper SL (1992) Overview of the stomatogastric nervous system. In: Dynamic biological networks: the stomatogastric nervous system (Harris-Warrick RM, Marder E, Selverston AI, Moulins M, eds), pp 1-30. Cambridge, MA: MIT.

Katz PS (1995) Intrinsic and extrinsic neuromodulation of motor circuits. Curr Opin Neurobiol 5:799-808.

Katz PS, Frost WN (1995a) Intrinsic neuromodulation in the Tritonia swim CPG: the serotonergic dorsal swim interneurons act presynaptically to enhance transmitter release from interneuron $\mathrm{C} 2$. J Neurosci 15:6035-6045.
Katz PS, Frost WN (1995b) Intrinsic neuromodulation in the Tritonia swim CPG: serotonin mediates both neuromodulation and neurotransmission by the dorsal swim interneurons. J Neurophysiol 74:2281-2294.

Katz PS, Harris-Warrick RM (1990) Neuromodulation of the crab pyloric central pattern generator by serotonergic/cholinergic proprioceptive afferents. J Neurosci 10:1495-1512.

Kawahara K, Suzuki M (1990) Interactions between locomotor and respiratory activities during hindlimb stepping on a stationary surface in decerebrate cats. Neurosci Lett 113:23-28.

Kilman V, Marder E (1996) Ultrastructure of the stomatogastric ganglion neuropil of the crab, Cancer borealis. J Comp Neurol 374:362-375.

Larson CR, Yajima Y, Ko P (1994) Modification in activity of medullary respiratory-related neurons for vocalizing and swallowing. J Neurophysiol 71:2294-2304.

Manor Y, Nadim F, Marder E, Nusbaum MP (1996) A model for the MCN1-activated gastric mill rhythm in the crab. Soc Neurosci Abstr 22:1438.

Marder E, Calabrese RL (1996) Principles of rhythmic motor pattern generation. Physiol Rev 76:687-717.

Marder E, Weimann JM (1992) Modulatory control of multiple task processing in the stomatogastric nervous system. In: Neurobiology of motor progamme selection (Kien J, McCrohan C, Winlow B, eds), pp 3-19. New York: Pergamon.

Marder E, Christie AE, Kilman VL (1995) Functional organization of cotransmission systems: lessons from small nervous systems. Invert Neurosci 1:105-112.

McCormick DA, Bal T (1994) Sensory gating mechanisms of the thalamus. Curr Opin Neurobiol 4:550-556.

Meyrand P, Simmers J, Moulins M (1991) Construction of a patterngenerating circuit with neurons of different networks. Nature 351:60-63.

Meyrand P, Simmers J, Moulins M (1994) Dynamic construction of a neural network from multiple pattern generators in the lobster stomatogastric nervous system. J Neurosci 14:630-644.

Moulins M, Cournil I (1982) All-or-none control of the bursting properties of the pacemaker neurons of the lobster pyloric pattern generator. J Neurobiol 13:447-458.

Mulloney B, Murchison D, Chrachri A (1993) Modular organization of pattern-generating circuits in a segmental motor system: the swimmerets of crayfish. Semin Neurosci 5:49-57.

Nagy F, Dickinson PS (1983) Control of a central pattern generator by an identified modulatory interneurone in crustacea. I. Modulation of the pyloric motor output. J Exp Biol 105:33-58.

Norris BJ, Coleman MJ, Nusbaum MP (1994) Recruitment of a projection neuron determines gastric mill motor pattern selection in the stomatogastric nervous system of the crab, Cancer borealis. J Neurophysiol 72:1451-1463.

Norris BJ, Coleman MJ, Nusbaum MP (1996) Pyloric motor pattern modification by a newly identified projection neuron in the crab stomatogastric nervous system. J Neurophysiol 75:97-108.

Nusbaum MP, Marder E (1988) A neuronal role for a crustacean red pigment concentrating hormone-like peptide: neuromodulation of the pyloric rhythm in the crab, Cancer borealis. J Exp Biol 135:165-181.

Nusbaum MP, Marder E (1989a) A modulatory proctolin-containing neuron (MPN). I. Identification and characterization. J Neurosci 9:1591-1599.

Nusbaum MP, Marder E (1989b) A modulatory proctolin-containing neuron (MPN). II. State-dependent modulation of rhythmic motor activity. J Neurosci 9:1600-1607.

Nusbaum MP, Cournil I, Golowasch J, Marder E (1989) Modulating rhythmic motor activity with a proctolin- and GABA-containing neuron. Soc Neurosci Abstr 15:366.

Nusbaum MP, Weimann JM, Golowasch J, Marder E (1992) Presynaptic control of modulatory fibers by their neural network targets. J Neurosci 12:2706-2714

Oku Y, Tanaka I, Ezure K (1994) Activity of bulbar respiratory neurons during fictive coughing and swallowing in the decerebrate cat. J Physiol (Lond) 480:309-324.

Otto D, Hennig RM (1993) Interneurons descending from the cricket subesophageal ganglion control stridulation and ventilation. Naturwissenschaften 80:36-38.

Pearson KG (1993) Common principles of motor control in vertebrates and invertebrates. Ann Rev Neurosci 16:265-298.

Perrins R, Weiss KR (1996) A cerebral central pattern generator in 
Aplysia and its connections with buccal feeding circuitry. J Neurosci 16:7030-7045.

Selverston AI, Miller JP (1980) Mechanisms underlying pattern generation in lobster stomatogastric ganglion as determined by selective inactivation of identified neurons. I. Pyloric system. J Neurophysiol 44:1102-1121.

Selverston AI, Moulins M (1987) The crustacean stomatogastric system. Berlin: Springer.

Skiebe P, Schneider H (1994) Allatostatin peptides in the crab stomatogastric nervous system: Inhibition of the pyloric motor pattern and the distribution of allatostatin-like immunoreactivity. J Exp Biol 194:195-208.

Steriade M, McCormick DA, Sejnowski T (1993) Thalamocortical oscillations in the sleeping and aroused brain. Science 262:679-685.
Wang Z, McCormick DA (1993) Control of firing mode of corticotectal and corticopontine layer $\mathrm{V}$ burst-generating neurons by norepinephrine, acetylcholine, and 1S,3R-ACPD. J Neurosci 13:2199-2216.

Weimann JM, Marder E (1994) Switching neurons are integral members of multiple oscillatory networks. Curr Biol 4:896-902.

Weimann JM, Meyrand P, Marder E (1991) Neurons that form multiple pattern generators: identification and multiple activity patterns of gastric/pyloric neurons in the crab stomatogastric system. J Neurophysiol 65:111-122.

Weimann JM, Marder E, Evans B, Calabrese RL (1993) The effects of SDRNFLRFamide and TNRNFLRFamide on the motor patterns of the stomatogastric ganglion of the crab Cancer borealis. J Exp Biol 181:1-26. 